\title{
Trends of Acute poisoning cases in a tertiary care hospital in Odisha, India: a prospective study
}

\author{
Narayan Prasad Modi ${ }^{1}$, Braja Kishore Dash ${ }^{2}$, Smita Satapathy ${ }^{3}$, \\ Anil Kumar Mohanty ${ }^{4}$ \\ 1,3,4 (Department of Pediatrics, SCB Medical college, Utkal University, India) \\ ${ }^{2}$ (Department of Forensic Medicine and Toxicology, SCB Medical college, Utkal University, India)
}

\begin{abstract}
Poisoning is a major problem in the pediatric population. However the offending agent and the associated morbidity and mortality vary from place to place and change over a period of time and in India limited data are available on its present trend.

Objectives: - To study the etio-clinical profile and outcome of childhood poisoning and intoxication.

Materials and methods: - This prospective study was carried out in patients who were admitted in pediatric wards and pediatric intensive care unit of S.C.B MCH \& SVPPGIP, Cuttack with history of ingestion of poison or intoxication or envenomation from March to November 2013.

Results: - A total of 288 poisoning cases of $<15$ years of age were studied. Majority (43\%) were under 5 years. Male accounting $70 \%$. Median duration between poisoning and presentation to our hospital being 17 hours. $65.7 \%$ received pre-referral treatment in the form of gastric lavage, atropine etc. Snake bite $(27.7 \%)$, kerosene $(17.3 \%)$ and insecticide $(12.4 \%)$ poisoning being the most common offending agents. Accidental exposure being $85.8 \%$. Suicidal cases being more common in $\geq 1$ years age children (68\%)(F:M 1.7:1).Most common presentation being respiratory distress $(32.5 \%)$, cellulitis of limb $(24.5 \%)$ \& altered sensorium $(18.3 \%)$. During treatment, $46.4 \%$ received antidote \& $46.37 \%$ received antibiotics. Mortality being 7\%.Overall, the outcome is good with $92 \%$ survival in our hospital.

Conclusion: Even though most common age group affected is still $\leq 5$ years, there has been a hike in suicidal rates in children. This highlights importance of spreading awareness in our community about the emerging epidemic of poisoning.
\end{abstract}

Keywords: childhood poisoning, snake bite, accidental exposure

\section{Introduction:}

Poisonings from intentional substance abuse, as well as from unintentional toxic exposures, remain a significant health concern for hospital emergency departments. With the control of infectious diseases, the contribution of poisoning to childhood mortality and morbidity has been increasing $(1,2)$. The substances responsible for accidental poisoning and the methods used for self-poisoning have changed considerably over time (3). Although the clinical outcome of these exposures is usually favorable, deaths do occur. Pediatric poisoning incidence in developing countries is poorly documented. Likewise in India limited data are available on morbidity and mortality related to poisoning in children, in particular the changes in its pattern over the years (4).

The present study was undertaken to determine in children the major offending agents, demographic pattern, mortality associated with them and change, if any in the type of poison by comparing data with previous studies available.

\section{Materials And Methods:}

This prospective study was carried out at S.C.B Medical College and SVPPGIP, CUTTACK over a period of 9 months from MARCH 2013 to NOVEMBER 2013. All cases of toxin exposure or poisoning whether bites, household poisons, agricultural or medicinal compounds were included. Those cases with food poisoning or drug reactions were excluded from our study. Detailed case history was obtained from the attendant regarding the nature of poison, time of consumption, circumstances of poisoning and immediate symptoms. Follow-up of the enrolled cases was done to know about the clinical course, complications, treatment received and the outcome. Data collected were tabulated and analyzed using SPSS.20. 


\section{Results:}

3.1 A total of 288 poisoning cases in age group of 6 month to 14 years were studied in the pediatric department of S.C.B MCH \& SVP PGIP, Cuttack. Out of 288 patients admitted there were 20 deaths (case fatality rate CFR being $6.9 \%)$.

3.2 FIGURE 1 shows the break-up of these cases on type of offending agents. Snake bite being the most common offending agent, accounting for 80 cases $(27.7 \%)$ with 6 deaths $(\mathrm{CFR}=7.5 \%)$. Kerosene poisoning $\{50$ cases $(17.3 \%)$ and 6 deaths $(\mathrm{CFR}=12 \%)\}$ and insecticide poisoning $\{36$ cases $(12.4 \%)$ and 1 death $(\mathrm{CFR}=2.8 \%)\}$ being the other more common offending agents. Figure 3 representing the deaths due to various poisoning.

3.3 TABLE 1 depicts the age and sex distribution of the cases enrolled. The male-to-female ratio was 2.4: 1(P value $=0.000)$. The age group most prone to poisoning was $0-5$ years with 124 children $(43 \%)$, while those in age group 5-10 years had 89 children (30.5\%) and >10years age group had 76 children (26.5\%). The mean (SD) age at admission was $7.05(3.8)$ years. $158(54.6 \%)$ patients were from urban areas as against $131(45.4 \%)$ from rural areas.

3.4 Among 288 patients, $65.7 \%$ received pre-referral treatment in the form of gastric lavage, atropine etc. Median duration between poisoning and presentation to our hospital being 17 hours. Lesser the duration, better is the outcome (TABLE 2).

3.5 FIGURE 2 shows the modes of poisoning. Accidental exposure, more common in children, being 247 cases (85.8\%) with 12 deaths $(\mathrm{CFR}=4.8 \%)$. Suicidal attempts found in 41 cases $(14.2 \%)$ with 8 deaths $(\mathrm{CFR}=19.5 \%)$. The deaths in accidental exposure being equally divided among snake bite and kerosene ingestion ( $30 \%$ each). (FIGURE 3)

3.6 TABLE 3 depicts the characteristics in self harm cases. Suicidal attempts being more common in children aged $\geq 11$ years [28 cases $(68 \%)$ ]. The male-to-female ratio was $1: 1.7$. Ingestion of insecticides was the major cause of poisoning, with 28 patients $(68.2 \%)$ with 1 death $(\mathrm{CFR}=3.5 \%)$. Other methods included partial hanging/ strangulation with 12 patients (29\%) and 7 deaths (CFR=58.3\%). (FIGURE 4).

3.7 Overall the most common presentations being respiratory distress $(32.5 \%)$, cellulitis of $\operatorname{limb}(24.5 \%) \&$ altered sensorium (18.3\%)( TABLE 4). During treatment, 46.4\% received antidote \& $46.37 \%$ received antibiotics. Mean duration $( \pm \mathrm{SD})$ of hospitalization was $4.6( \pm 3.1)$ days.

3.8 Mortality of 7\% was reported (TABLE 5) being higher in age group 5- 10 years [ 8 cases ( $40 \%$ )]. Overall, the outcome is good with $92 \%$ survival in our hospital.

\section{Discussion:}

4.1 Poisoning in children comprises a significant component of injury- related morbidity and mortality. (1). Pediatric poisoning incidence in developing countries is poorly documented. There are few data on the changing trends in incidence and causative agents for developing countries (4). The true incidence of exposures and poisonings within the pediatric population of Odisha for the study period could not be calculated. A true estimate requires inclusion of children presenting to public and private facilities and this information is not available. In this study, we have tried to project the recent changing trends in pediatric poisoning cases presenting to our hospital over a period of 9 months.

4.2 The age ranged from 6 months to 14 years and compromised of three groups: group 1. ( $\leq 5$ years), group 2. (5years- 10years), group 3. (> 10years). Children below the age $\leq 5$ years have been affected more than other groups in concordance with many reports in the literature (5-7). The vulnerability of the preschool age group could be due to inherent inquisitiveness and high oral exploratory activity aided by their newly acquired mobility and hand skills. There was a higher incidence of poisoning in males (70.8\%) than in females $(29.2 \%)$ in all age groups, ( $p$ value $=0.000$...reflects significant association between age and sex). This is in corroboration with other studies $(8,9)$. The more active and restless nature of males as compared to their female counterparts could be the responsible factor.

4.3 The most common mode of poisoning was accidental (85.8\%) and the intentional mode contributed $14.2 \%$ to the total. In Gr. $1 \& 2$, the mode was mostly accidental as in many other studies(10,11), whereas Gr. 3 showed dominance of the intentional mode reportedly common among adolescents $(6,12)$. Suicide attempts among teenagers could be due to an individual's frustration, inadequacy to cope with some immediate situation, impulsive behavior, school stress and conflicts with parents, all leading to emotional insecurity.

4.4 The pattern of poisoning shows a variable trend as compared to various earlier hospital based Indian studies (13-15). In India, variation in type and frequency from different parts of the country largely due to geographical and socio-economic conditions has been noticed, but accidental poisoning has been very frequent below 5 years of age with the dominance of males. Though most studies from India report a high incidence of poisoning due to kerosene (13-16), the present study shows the highest incidence due to snake bite (27.7\%). There is not much literature implicating snake bite as poisoning agents in India (17). The difference reported may be due to seasonal variation in case admission and more referral of snake bite cases to our govt hospital due to availability 
of ASV free of cost to patient. Referral of other cases to various private sector hospitals may also account for the difference. Next to snake bite, kerosene ingestion (17.3\%) remains the most common offending agent. Kerosene is the commonest agent implicated because it is still used as a cooking fuel by the low socio-economic class, its storage in easily accessible places \& its color which is often mistaken for soft drink. Insecticide ingestion $(12.4 \%)$ comes next, including both accidental exposure and intentional use. A high incidence of poisoning due to household pesticides is well documented in the literature $(18,19)$. Our study also records poisoning due to cleaning agents in concordance with other reports (6, 7, and 119). Although most of these household products are deemed to be necessities of daily living, none of them can ever be considered safe, especially for children. A degree of safety can only be achieved if they are used in the prescribed manner and in ways recommended for safe storage. It therefore seems that household products pose a potential risk to children and ways to control their easy accessibility should be devised to reduce pediatric exposures. Educating parents and caretakers about how the home environment may pose potential risks that could lead to an episode of accidental poisoning, and the introduction of childproof containers can help in averting such exposures to a large extent.

4.5 The highest incidence of poisoning among the agricultural pesticides was due to organophosphates (24 cases out of 36 cases of insecticide poisoning). It was consumed intentionally by children in Gr. 3 and improper storage was mainly responsible. Consumption of agricultural pesticides by children is well documented (20, 21).Substituting less lethal pesticides, reducing the concentration of active ingredients, improving packaging and controlling easy access by proper storage can help to reduce the problem to a great extent.

4.6 Among plants, cases of oleander seed ingestion were common, exclusively accidental, more in age $<8$ yrs. It's unlike Sri Lanka where it is commonly ingested by females with suicidal intent (22). In a number of cases the agent implicated was not known. (15\%).

4.7 Present study observed predominance of poisoning in urban children which was in agreement with Mansard $\mathrm{N}$ et al. (23) study from Karachi. Also the incidence of poisoning was found to be highest in lower income group followed by lower middle income group which was in concordance with work in Karachi $(23)(80 \%$ lower income group, $19 \%$ middle income group and $1 \%$ fair income group). These observations can be attributed to higher availability of various poisons to urban children due to the more use of various chemical products in urban areas. While increased incidence in lower income group can be attributed to lower level of education, improper storage of chemicals \& household products and lower level of care towards the child.

$4.87 \%$ mortality was found in our series. Similar mortality incidence was reported from Lalitpur (UP), Nepal \& Oslo [24, 25].

\section{Figures and Tables}

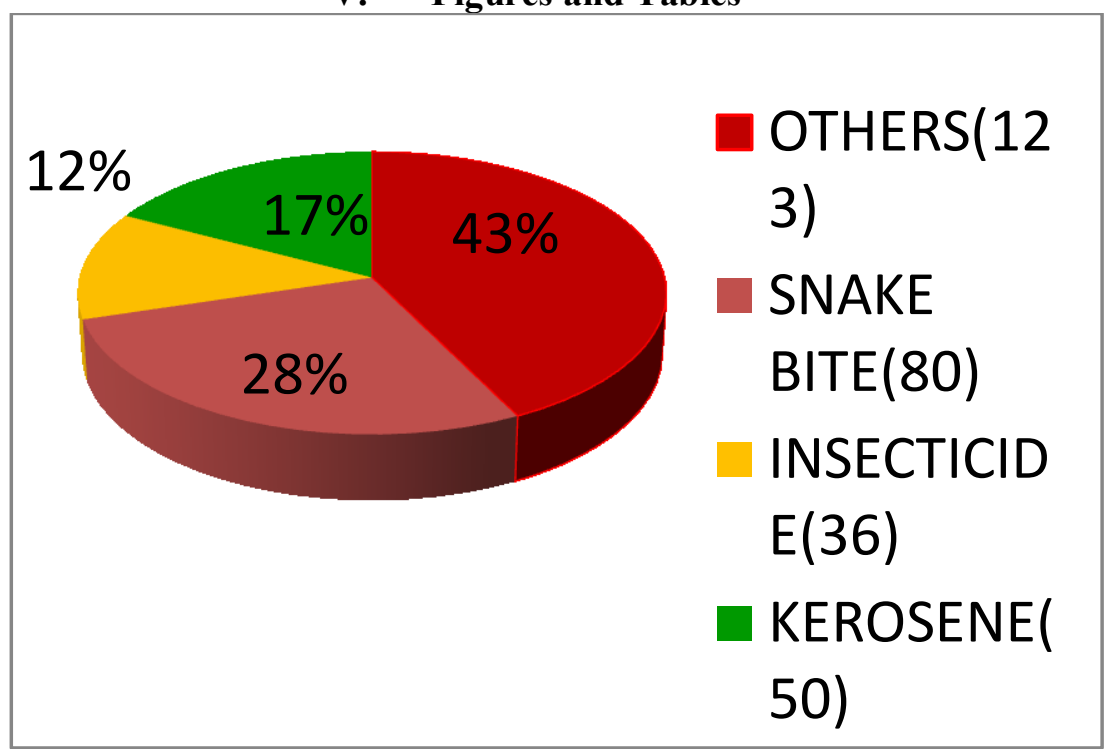

F Igure 1: Distribution Of Poisoning Cases By Types Of Offending Agents 
TABLE 1: AGE AND SEX DISTRIBUTION

\begin{tabular}{|l|l|l|l|}
\hline AGE(yrs) & MALE & FEMALE & \\
\hline $\mathbf{0 - 5}$ & 104 & 20 & $124(43 \%)$ \\
\hline $\mathbf{5 - 1 0}$ & 61 & 28 & $89(30.9 \%)$ \\
\hline $\mathbf{1 0 - 1 5}$ & 39 & 36 & $75(26.1 \%)$ \\
\hline TOTAL & $\mathbf{2 0 4 ( 7 0 . 8 \% )}$ & $\mathbf{8 4}(\mathbf{2 9 . 2 \% )}$ & \\
\hline
\end{tabular}

TABLE 2:- RELATION BETWEEN PRESENTING TIME AND OUTCOME

\begin{tabular}{|l|l|l|}
\hline TIME & SURVIVAL & DEATH \\
\hline$<\mathbf{2 4 h r}$ & $96.8 \%$ & $3.2 \%$ \\
\hline $\mathbf{2 4 - 4 8 h r}$ & $93.3 \%$ & $6.7 \%$ \\
\hline$>\mathbf{4 8 h r}$ & $90.1 \%$ & $9.9 \%$ \\
\hline
\end{tabular}

FIGURE 2:- MODES OF POISONING

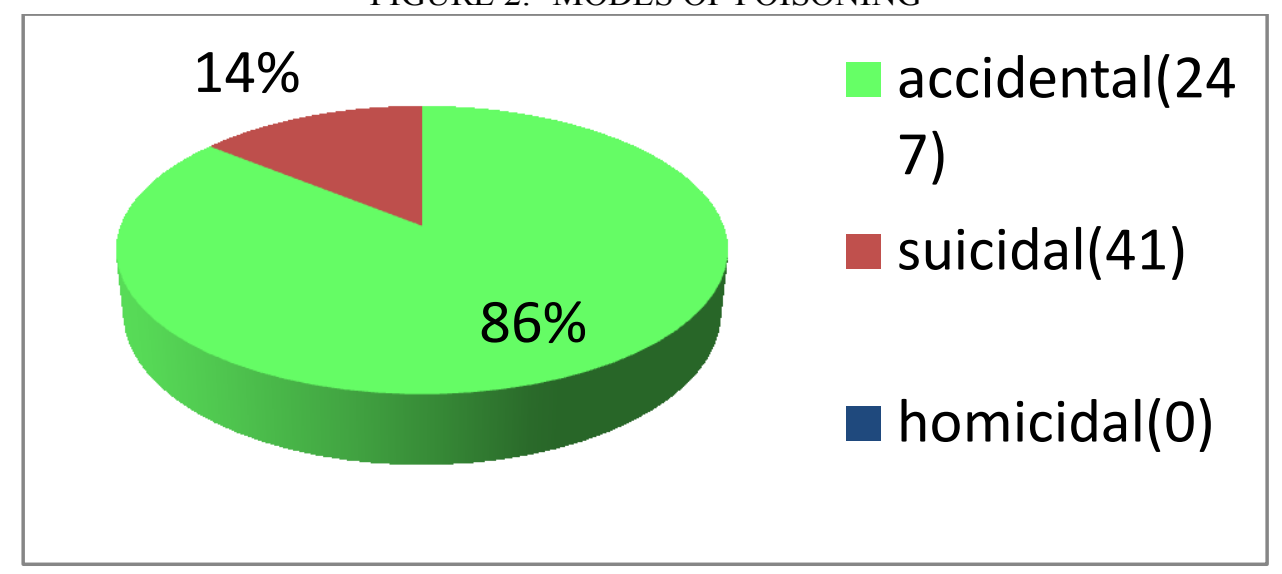

FIGURE 3:- DEATH DISTRIBUTION

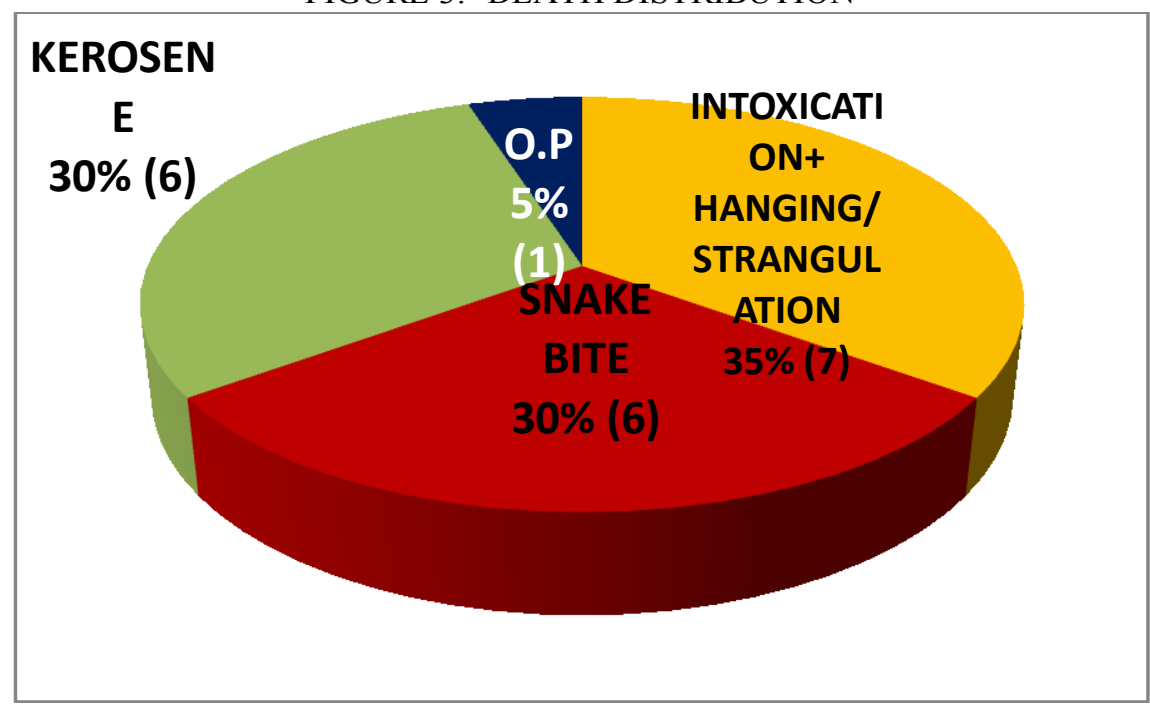


TABLE 3:- AGE AND SEX CHARACTERISTIC IN SUCIDAL CASES

\begin{tabular}{|l|l|l|l|}
\hline AGE(YRS) & MALE & FEMALE & TOTAL \\
\hline$<\mathbf{1 1}$ & 6 & 7 & 13 \\
\hline$\geq \mathbf{1 1}$ & 9 & 19 & 28 \\
\hline TOTAL & $\mathbf{1 5}$ & $\mathbf{2 6}$ & $\mathbf{4 1}$ \\
\hline
\end{tabular}

FIGURE 4:- MODES OF POISONING

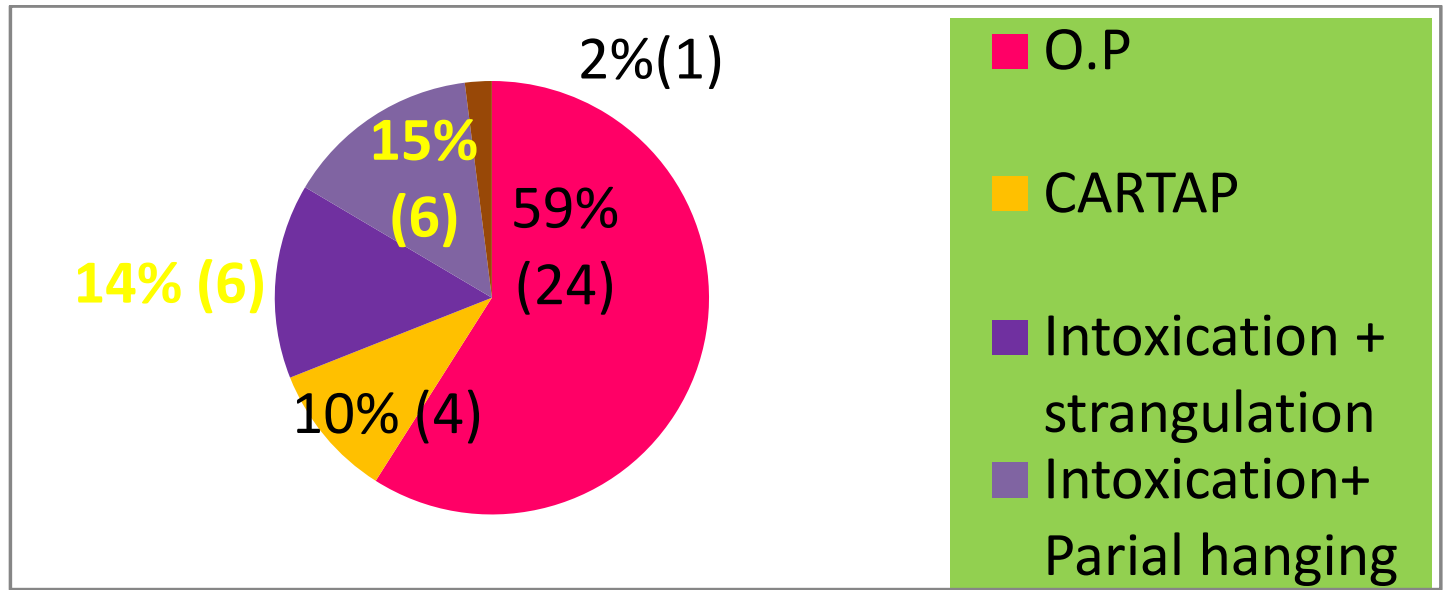

TABLE 4:- MODES OF PRESENTATION

\begin{tabular}{|l|l|}
\hline Signs \& Symptoms & Number \\
\hline RESP & 94 \\
\hline MSK & 90 \\
\hline G.I & 80 \\
\hline CNS & 64 \\
\hline KIDNEY & 36 \\
\hline CVS & 35 \\
\hline HEMATOLOGY & 14 \\
\hline
\end{tabular}

TABLE 5:- OUTCOME

\begin{tabular}{|l|l|}
\hline DISCHARGE & $179(61.9 \%)$ \\
\hline DEATH & $20(7 \%)$ \\
\hline LAMA & $89(31.1 \%)$ \\
\hline
\end{tabular}

\section{Conclusion}

Acute poisoning, a common pediatric emergency is one of the important causes of morbidity and mortality in children especially in developing countries. Thousands of innocent children under the age of five years are poisoned accidentally every year throughout the world, mainly due to their innovative and exploratory nature and mouthing tendencies $(5,26,27)$. Poisoning is most common in $0-5$ years age group as far as pediatric poisoning is concerned; also it is more frequent in males of urban areas especially in lower income group.

The present study does not represent the exact incidence of childhood poisoning in our country, which could be higher or even variable, because there is no central registry of poisoning cases in general and there could also be underreporting of cases to the Centre. No doubt many hospital based studies do give some idea of incidence, but such studies may not truly represent the community at large, as many calls especially from rural areas and accidents due to occupational exposure never get reported, for many reasons. Because the main causes of pediatric poisoning are negligence and ignorance, many deaths and disabling sequelae could very easily be prevented if more attention were given to implementing preventive measures at home. So increased public 
awareness of risks, especially of household products, could reduce the occurrence of accidental pediatric poisoning to a great extent.

There are a number of hospital based epidemiological studies on childhood poisoning in India implicating different agents and all emphasize the implementation and improvement of prevention programmers, which can be aided to a large extent by the identification of high risk circumstances, susceptible age groups, chemical substances and commercial products involved in pediatric poisoning cases(13-15). The Poisons Information Centre which forms an important component of the Poisons Control Programmed plays an important role in the management of poisoning. In India, this particular health aspect received attention a few years back and the first National Poisons Information Centre (NPIC ) was established in the Department of Pharmacology at the All India Institute of Medical Sciences in 1995(28). The NPIC provides round- the-clock service giving information on management of various types of poisonings to physicians all over the country on telephone and Fax. Establishment of such centers all over the country with easy accessibility and implementation of strict policies with generation of awareness among people is the concept paramount to providing care for a growing pediatric population

\section{References}

[1] Lewis HH, Cronje RE, Naude SP, van den Berg C (1989) Accidental poisoning in childhood. S Afr Med J 76: 429-431.

[2] Pearn J, Nixon J, Ansford A, Corcoran A (1984) Accidental poisoning in childhood: five year urban population study with 15 year analysis of fatality. Br Med J (Clin Res Ed) 288: 44-46

[3] Townsend E, Hawton K, Harriss L, et al. Substances used in deliberate self-poisoning: trends and associations with age, gender, repetition and suicide intent, 1985 - 1997. Soc Psychiatry Psychiatr Epidemiol 2001; 36:228 - 234

[4] SK Gupta, SS Peshin, A Srivastava, T Kaleekal and TV Pandian: Epidemiology of acute poisoning. Natl Med J Ind 15, 177 (2002)

[5] K Goto, Y Endoh, Y Kuroki and T Yoshioka: Poisoning in children in Japan. Ind J Paedtr 64, 461-468 (1997)

[6] M Lifshitz and V Gavrilov: Acute poisoning in children. Isr Med Assoc J 2, 504-506 (2000)

[7] MA McGuigan: Common culprits in childhood poisoning: epidemiology, treatment and parental advice for prevention. Pediatr Drugs 1, 313-324 (1999)

[8] MR Repetto: Epidemiology of poisoning due to pharmaceutical products, Poison Control Centre, Seville, Spain. Eur J Epidemiol 13, 353-356 (1997)

[9] MR Repetto: Pediatric poisonings due to cleansing agents reported in 1994 to the Toxicological Information Service of Seville, Spain. Vet Hum Toxiol 38, 435-437 (1996)

[10] M Kotwica and A Rogaczewska: Causes of poisoning in children during the period 1990-1993. Przegl-Lek 53, 329-333 (1996)

[11] Jaraczewska W and Kotwica M: Acute poisoning with drugs-A review of the data collected at the NPIC during the period 19911995. Przegl-Lek 54, 737-740 (1997)

[12] Hawton K, Fagg J and Simkin S: Deliberate self poisoning and self injury in children and adolescents under 16 yr of age in Ox ford, 1976-1993. Br J Psychiatry 169, 202-208 (1996)

[13] S Gupta, YC Govil, PK Misra, R Nath and KL Srivastava: Trends in poisoning in children: Experience at a large referral teaching hospital. Natl Med J Ind 11, 166-168 (1998)

[14] A Mehta, RR Kasla, SB Bavdekar, GS Hathi and SY Joshi: Acute poisonings in children. JIMA 94, 219-220 (1995)

[15] A Singh and SR Choudhary: Accidental poisoning in children. Ind Pediatr 33, 39-41 (1996)

[16] AK Dutta, A Seth, PK Goyal, V Aggarwal, SK Mittal, and R Sharma: Poisoning in children: Indian Scenario. Ind J Pediatr 65, 365$370(1998)$

[17] NK Aggarwal, MS Bhatia and BBL Aggarwal: Deaths due to poisoning in children. Ind Pediatr 36, 415-416 (1999)

[18] D Sumner and R Langley: Pediatric pesticide poisoning in the Carolinas; an evaluation of the trends and proposal to reduce the incidence. Vet Hum Toxicol 12, 101-103 (2000)

[19] YR Leveridge: The pattern of poisoning in Costa Rica during 1997. Vet Hum Toxicol 41, 100-102 (1999)

[20] P Menon and AH Kodama: Hawii Poison Center data reveals a need for increasing hazard awareness about household products. Hawaii Med J 57, 476-478 (1998)

[21] MF Spann, JM Blondell and KL Hunting: Acute hazards to young children from residential pesticide exposure. Am J Pub Health 90, 971-973 (2000)

[22] M Eddleston, CA Ariaratnam, WP Meyer, G Perera, AM Kularatne, S Attapattu: Epidemic of self poisoning with seeds of yellow oleander tree (Thevetia peruiana) in northern Sri Lanka. Trop Med Int Health 4, 266-273 (1999)

[23] Mansard N, Saad SM, Manzar B, Fatima SS (2010) The study of etiological and demographic characteristics of acute household accidental poisoning in children--a consecutive case series study from Pakistan. BMC Pediatr 10: 28

[24] Ghai OP, Gupta P (2004) Poisonings and accidents. Ghai essential pediatrics (6th ed). CBS Publishers and distributers 640.

[25] Jacobsen D, Halvorsen K, Marstrander J, Sunde K, Bakken AF (1983) Acute poisonings of children in Oslo. A one year prospective study. Acta Paediatr Scand 72: 553-557.

[26] JL Hoy, LM Day, J Tibballs and SJ Ozanne: Unintentional poisoning hospitalizations among young children in Victoria. Inj Prev 5, 31-35 (1999)

[27] LF Mc Caig and CW Burt: Poisoning related visits to emergency departments in United States,1993-1996. J Toxicol-Clin Toxicol 37, 817-826 (1999)

[28] SB Lall and SS Peshin: Role and functions of Poisons Information Centre. Ind J Paedtr 64, 443-449 (1997) 